\title{
A FIGURA DO IDOSO NA LITERATURA INFANTIL: UM COMPARATIVO ENTRE AS OBRAS GUILHERME AUGUSTO ARAÚJO FERNANDES E VÓ, PARA DE FOTOGRAFAR!
}

\author{
THE FIGURE OF THE ELDERLY PERSON IN \\ CHILDREN'S LITERATURE: A COMPARISON \\ BETWEEN THE BOOKS GUILHERME AUGUSTO ARAÚJO \\ FERNANDES AND VÓ, PARA DE FOTOGRAFAR!
}

Estella Maria Bortoncello Munhoz"

Verônica Bohm***

\begin{abstract}
Resumo: Este artigo tem como objetivo analisar como a velhice é representada em duas obras infantis publicadas no Brasil em diferentes décadas. Para isso, o trabalho discute conceitos relacionados à velhice a partir de autores como Beauvoir (2018) e Baltes (1987), e analisa os livros ilustrados: Guilherme Augusto Araújo Fernandes (1984) e Vó, para de fotografar! (2017), que também permitem incluir na análise uma reflexão sobre relações geracionais e memórias. Com posse do corpus literário, é feita uma análise relacionando aspectos que aproximam e diferenciam as obras, discutindo a forma como o idoso é retratado no texto verbal e na ilustração. Os resultados apontam que a obra atual rompe com estereótipos negativos relacionados à velhice, enquanto que, na obra mais antiga, há a presença de características tradicionalmente associadas à última fase do ciclo vital. Contudo, ambas têm importante valor, visto que a velhice é composta por um grupo de pessoas singulares, diversas, embora possam ter alguns aspectos semelhantes.
\end{abstract}

Palavras-chave: Literatura infantil. Velhice. Idoso.

Aвstract: This article aims to analyze how old age is represented in children's books published in Brazil in different decades. For this, the research discusses concepts

\footnotetext{
"Mestranda em Letras e Cultura, especialista em Literatura Infantil e Juvenil e bacharel em Design pela Universidade de Caxias do Sul. E-mail: embmunhoz@ucs.br.

* Doutora em Educação pela Universidade Federal do Rio Grande do Sul, especialista em Gerontologia pela Sociedade Brasileira de Geriatria e Gerontologia e graduada em Psicologia pela Universidade de Caxias do Sul. Professora na Universidade de Caxias do Sul. E-mail: vbohm@ucs.br.
} 
related to old age from authors such as Beauvoir (2018) and Baltes (1987), and analyzes the illustrated books: Guilherme Augusto Araújo Fernandes (1984) and Vó, para defotografar! (2017), which also allow a reflection on generational relationships and memories. With possession of the literary corpus, an analysis is made relating aspects that approximate and differentiate the books and how the elderly person is portrayed in the verbal text and in the illustration. The results show that the current book breaks with stereotypes related to old age, while in the oldest book, there is the presence of characteristics traditionally associated with the last phase of the life cycle. However, both have an important value, since old age is composed of a group of natural persons, although they may have some similar aspects.

KEYwords: Children's literature. Old age. Elderly person.

\section{INTRODUÇÃo}

Valter Hugo Mãe, em A máquina de fazer espanhóis, retrata a solidão de um senhor de pouco mais de sessenta anos deixado em um lar de idosos. Os moradores daquele lugar, segundo a impressão do protagonista, eram "todos a mesma coisa, um conjunto de abandonados a descontar pó ao invés de areia na ampulheta do tempo" (MÃE, 2016, p. 28). Do mesmo modo, Rubem Alves, em sua obra As cores do crepúsculo, também retrata a velhice como exclusão:

Sim, há muito tempo eu tinha consciência de não ser mais jovem. [...] Eu era um estranho. Os colegas professores, em início de carreira, dirigiam-se a mim como 'senhor'. O fato é que eu não era convidado para suas festinhas. Eu era um estranho (ALVES, 2008, p. 35).

Se uma das maiores consequências do tempo é a velhice, ainda que tipificada como um período de abandono e fragilidade, as formas como cada indivíduo materializa essa fase em sua vida é diferente e sofre constantes modificações de acordo com influências sociohistóricas e culturais. Assim, muitos conceitos ligados à velhice mudaram ao longo dos anos, porque os idosos e a sociedade também se transformaram.

Nesse sentido, os processos culturais impactam fortemente no envelhecer e na maneira como as pessoas idosas são vistas. No mundo da pós-modernidade, da rapidez, da agilidade e da descontinuidade, o pensado posto, pronto e definido se liquefaz (BAUMAN, 2001). É difícil definir claramente quem é a pessoa idosa de hoje, até porque cada pessoa envelhece de maneira singular, pois o envelhecimento é um processo heterogêneo, influenciado por questões biopsicossociais e históricas (BALTES, 1987). No entanto, é possível refletir sobre as concepções do idoso do passado e do presente, afinal, a representação que se tem dessa figura muda ao longo do tempo, tendo como lastro os valores que permeiam cada sociedade. 
O conceito ocidental sobre o envelhecimento ainda é repleto de preconceitos e estereótipos. Para Beauvoir (2018, p.10), é preciso se reconhecer nas pessoas idosas do nosso entorno "se quisermos assumir em sua totalidade nossa condição humana". Para enxergar o idoso sem as nebulosas ideias construídas sobre essa faixa-etária, faz-se necessário, segundo tese defendida pela autora, ser empático e ir além de ideias tipificadas, reconhecendo não apenas o quanto todos estamos envelhecendo, mas também o fato de os idosos não fazerem parte de um grupo homogêneo e, em seus diferentes modos de ser, contribuírem na formação social e cultural.

Atualmente, com a expectativa de vida mais longa, o número de idosos aumentou significativamente, acarretando em transformações nas relações intergeracionais. Assim, grupos mais jovens podem ter contato com pessoas mais velhas, em uma espécie de troca mútua. Dessa forma, Feixa e Leccardi (2010) destacam o indivíduo como ser que se relaciona com as gerações passadas e com as que virão, em um constante processo de continuidades e descontinuidades.

A representação do idoso, mesmo com as modificações sofridas pela figura ao longo do tempo, permanece, em muitos casos, solidificada. Não raro, a pessoa é vista como alguém frágil, debilitada e esquecida, por ser, muitas vezes, improdutiva nos moldes da sociedade utilitarista. Ainda assim, "toda sociedade tende a viver, a sobreviver; exalta o vigor e a fecundidade, ligados à juventude; teme o desgaste e a esterilidade da velhice" (BEAUVOIR, 2018, p. 47).

Essa ideia corrobora o conceito de representações sociais. Essas representações são ideias presentes na mente de uma comunidade e compartilhadas como um todo de forma consensual. No caso da pessoa idosa, há uma ideia homogeneizadora de atribuir, aos sujeitos na fase da velhice, adjetivos como vulneráveis, incapazes, doentes, quietos e recolhidos ao ambiente doméstico. Tais características podem estar presentes na velhice, mas não representam uma condição homogênea. Segundo Reis e Ceolim (2007), o mito da dependência do idoso é posto em dúvida por trabalhos norteados de uma concepção mais positiva da velhice: consideram a maioria dos idosos como capazes de realizar as atividades da vida diária sem ajuda, pois são suficientemente saudáveis e autônomos para tal. Por isso, conforme afirma Guareschi (2000), as representações sociais não são conceitos fixos, e podem ir se modificando nas inter-relações do cotidiano. Assim, com o crescente aumento de pessoas mais velhas na sociedade ${ }^{1}$ as próprias transformações na vida humana, aos poucos, a visão em relação aos idosos tem sido modificada.

No livro infantil ilustrado, ${ }^{2}$ as figuras têm forte impacto sobre os pequenos, visto que "a imagem de um livro no psiquismo de uma criança pode se estender por toda a vida adulta"

\footnotetext{
${ }^{1}$ Segundo dados do Laboratório de Demografia e Estudos Populacionais (UFJF), com base na pesquisa de José Diniz, uma das características da atual dinâmica demográfica mundial é o processo de envelhecimento populacional, isto é, o aumento do número absoluto e do percentual de idosos no conjunto da população. Esse fenômeno ocorre desde 1950, mas foi intensificado ao longo do século XXI.

${ }^{2}$ Obras em que a imagem é espacialmente predominante em relação ao texto (NIKOLAJEVA; SCOTT, 2011)
} 
A FIGURA DO IDOSO NA LITERATURA INFANTIL: UM COMPARATIVO ENTRE AS OBRAS GUILHERME AUGUSTO ARAÚJO FERNANDES E VÓ, PARA DE FOTOGRAFAR!

(OLIVEIRA, 2008, p. 45). Nesse sentido, a literatura é um fator importante de influência nas representações sociais e nas mudanças de pensamentos. Assim, texto verbal e visualidade constroem a significância juntos, já que a ilustração, como expressão artística, não pode ser subordinada exclusivamente ao texto literário na relação texto-imagem (OLIVEIRA, 2008).

A visão do envelhecimento perpetuada por livros infantis é, ao mesmo tempo, um reflexo da sociedade e um meio de transformar o olhar em relação aos idosos (FERREIRA et al., 2015). Assim, em relação às crianças, a educação formal e a informal são importantes maneiras de ampliar a visão dos pequenos quanto à velhice e estimulá-los a pensar sobre o idoso de maneira mais adequada aos novos contextos sociais. Ressalta-se ainda que, além das possibilidades de reflexão acerca do idoso, as obras literárias também permitem a fruição do pequeno leitor, que, diante de palavras e imagens, encontra diversos sentidos para a leitura.

Se na literatura muitas representações sociais são formadas e/ou dissipadas, é importante analisar como livros de diferentes épocas constroem o olhar sobre o idoso. Para isso, neste artigo, o objetivo principal foi comparar as representações do idoso em dois livros ilustrados publicados no Brasil em diferentes períodos históricos. Para tal, selecionaram-se as obras Guilherme Augusto Araújo Fernandes (1984), de autoria de Mem Fox, ilustrada por Julie Vivas, e a obra Vó, para de fotografar! (2017), escrita por Guilherme Karsten e ilustrada por Ilan Brenman. Ainda que a primeira obra seja de origem estadunidense e a segunda brasileira, a maior diferença das histórias é a forma como o idoso é retratado nas mais de três décadas entre as duas narrativas.

\section{Os IDOSOS NA LITERATURA}

\section{Guilherme Augusto Araújo Fernandes}

A obra Guilherme Augusto Araújo Fernandes, da editora Brinque-book, é um clássico da literatura infantil, conquistando o título de Altamente Recomendável Tradução/Criança pela Fundação Nacional do Livro Infantil e Juvenil (FNLIJ), em 1996. Narrada em terceira pessoa, por um narrador onisciente, a história trata da relação entre um menino e uma idosa que perdeu sua memória, abordando, a partir do fato, a questão da velhice e da interação entre diferentes gerações.

Logo na capa, o leitor já consegue perceber as diferenças entre uma senhora e um menino. Uma cena muito similar está representada também dentro do livro. Observando a ilustração, é possível fazer inferências sobre o ciclo inicial e final da vida por meio da ilustração dos dois personagens. Assim, desde a capa, o leitor é apresentado à narrativa, já que a contribuição dos paratextos para o livro ilustrado é muito importante, em especial porque 
costumam carregar uma porcentagem significativa das informações verbais e visuais do livro (NIKOLAJEVA; SCOTT, 2011).

Figura 1: Obra Guilherme Augusto Araújo Fernandes
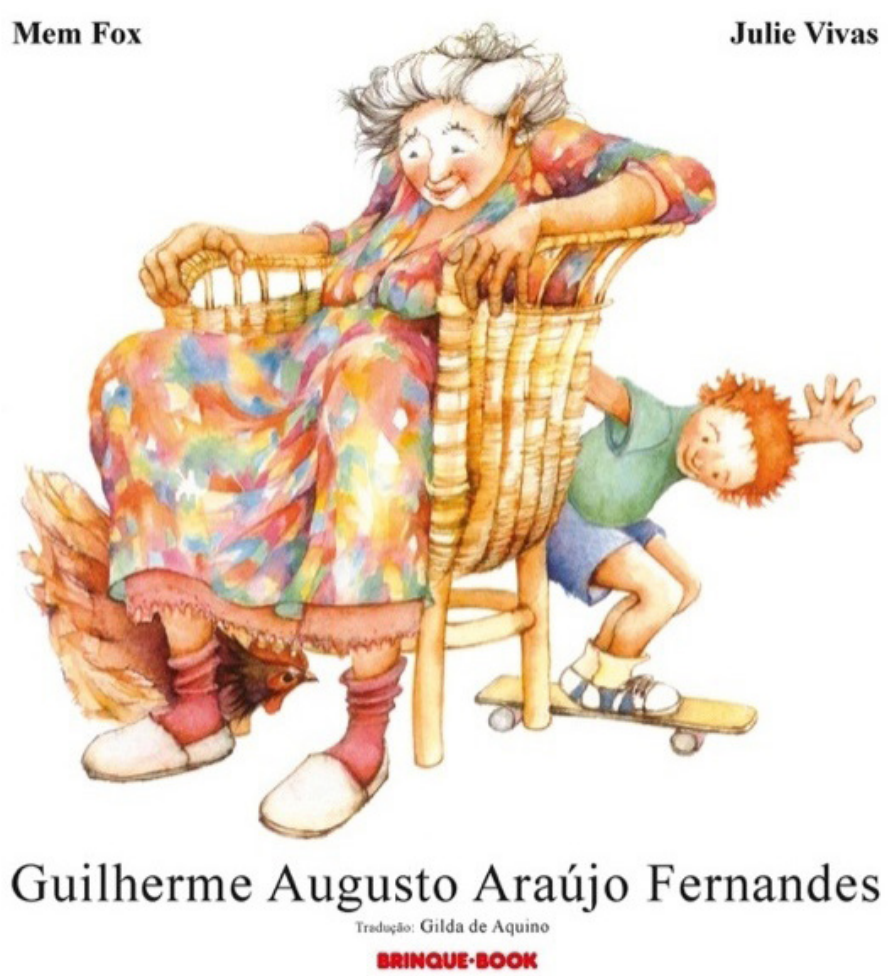

Fonte: Fox (2005)

Nas páginas internas, a história inicia marcando divisões entre a velhice e a juventude. O menino protagonista, Guilherme Augusto Araújo Fernandes, mora ao lado de um asilo, assim, a primeira ilustração da narrativa apresenta um muro que divide a criança brincalhona e ativa da morada dos idosos quietos e estáticos. Essa cena contrapõe infância e velhice - sendo algo naturalmente diferente - e gera uma reflexão sobre o conceito do idoso como um grupo homogêneo, à parte da sociedade e, inclusive, separado fisicamente por muros das outras pessoas. Para Ramos (2015, p. 205), nas histórias infantis, "a velhice muitas vezes aparece em forte relação de oposição com a juventude, sendo perceptível uma (de)marcação de fronteiras entre essas duas fases da vida". 
A FIGURA DO IDOSO NA LITERATURA INFANTIL: UM COMPARATIVO ENTRE AS OBRAS GUILHERME AUGUSTO ARAÚJO FERNANDES E VÓ, PARA DE FOTOGRAFAR!

Figura 2: Ilustração Guilherme Augusto Araújo Fernandes

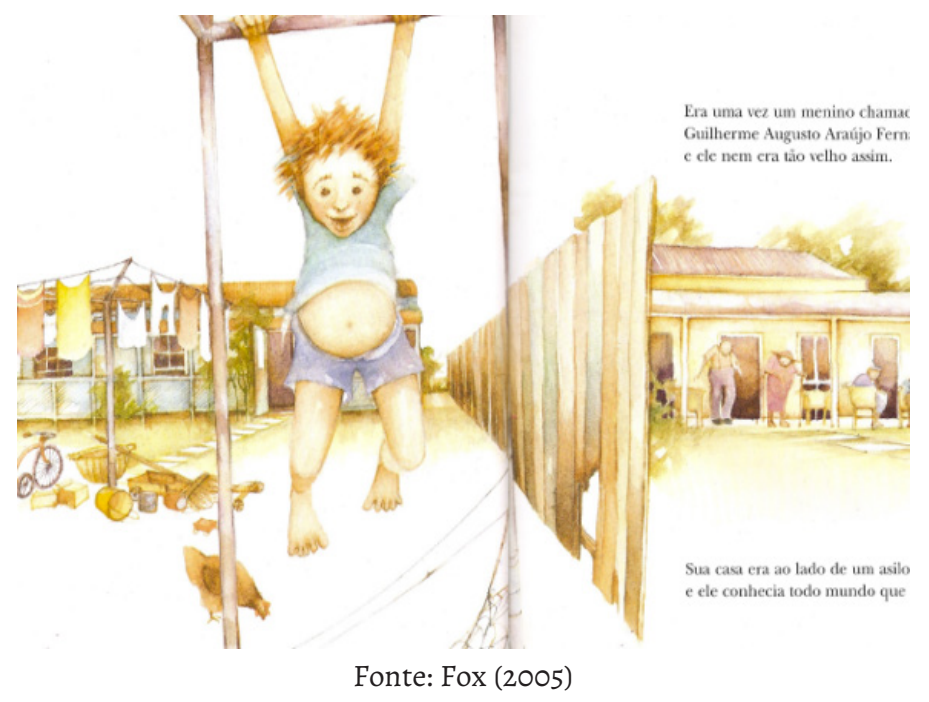

Ao longo da história, porém, é possível conhecer alguns desses idosos moradores do asilo e, como aspecto positivo, a obra mostra as individualidades de cada personagem. No texto, o protagonista "gostava da Sra. Silvano que tocava piano. Ele ouvia as histórias arrepiantes que lhe contava o Sr. Cervantes. Ajudava a Sra. Mandala que andava com uma bengala. E admirava o Sr. Possante que tinha voz de gigante" (FOX, 2005, p. 12-13). Por esse viés, a criança, ao ultrapassar o muro, reconhece a heterogeneidade dos velhos da história.

Na obra, há uma idosa especial: Antônia Maria Diniz Cordeiro, adorada pelo protagonista por ter quatro nomes como ele. Um dia, o menino ouve seus pais falando sobre Dona Antônia e descobre o quanto a senhora havia perdido a memória. A mãe dizia: "Coitada da velhinha [...]. Também, não é para menos, ela já tem noventa e seis anos” (FOX, 2005, p. 18). Nesse trecho da narrativa, é possível refletir sobre o papel de idoso na condição de ser vulnerável e a constante associação, muitas vezes equivocada, da velhice com a doença, ideia corroboradora dos apontamentos de Ramos (2015), para quem é comum a associação de velhice às fragilidades fisiológicas e doenças.

No decorrer da história, ao descobrir a situação da amiga idosa, como alguém desprovida de memória, o protagonista resolve conversar com os demais moradores do lar para saber o significado do termo memória. Esse aspecto de ouvi-los é um destaque da obra, pois é uma forma de reconhecer o potencial dos idosos como sujeitos de opiniões próprias, vivências e meios de enxergar o mundo. De acordo com Fernandes (2013), as pessoas idosas contam, lembram e aconselham, mas é preciso que alguém os ouça.

Para alguns personagens do lar de idosos, memória é algo quente, algo antigo, que faz rir, chorar e pode até valer ouro. Após a escuta sobre as diferentes acepções de memória, o menino resolve recolher diversos objetos correspondentes às distintas descrições feitas: 
conchas, marionete, medalha de seu avô, bola de futebol e um ovo fresquinho. Guilherme Augusto decide levar todos esses elementos até Dona Antônia para que ela lembre de suas memórias. Esse comportamento tem resultados imediatos: "e então ela começou a se lembrar" (FOX, 2005, p. 17). A história termina com a criança e a idosa juntos e felizes, rememorando acontecimentos antigos da vida de Dona Antônia.

Esse final permite distintas interpretações. Em um primeiro plano, a forma como a criança ajuda Dona Antônia demonstra respeito e aponta as gerações mais novas como responsáveis por pensar e agir em prol do bem-estar social de pessoas mais velhas. Há também o fato de a idosa ter conseguido recobrar suas memórias, o que sinaliza para a possibilidade de cura/recuperação de quadros clínicos negativos também na velhice, rompendo com o estereótipo de que o idoso sempre tem lapsos de esquecimento e nada há para ser feito para reverter ou atenuar a situação.

Outro elemento importante é que, na página de guarda, ${ }^{3}$ Dona Antônia está desenhada sentada de costas e, na ilustração final da história, a cadeira está vazia e voltada para a frente, ou seja, é como se, com a ajuda da criança, a idosa pudesse ter conseguido se erguer e adquirido um pouco mais de independência. Segundo Nikolajeva e Scott (2011, p. 317), "na maioria dos livros ilustrados, as guardas iniciais e finais são idênticas. Entretanto, podem ser usadas para enfatizar as mudanças que ocorreram ao longo do livro". É por isso que todos os detalhes da obra corroboram na inferência de sentidos que dialogam com a narrativa.

Figura 3: Ilustrações de abertura (Dona Antônia sentada) e fechamento (cadeira vazia) da obra
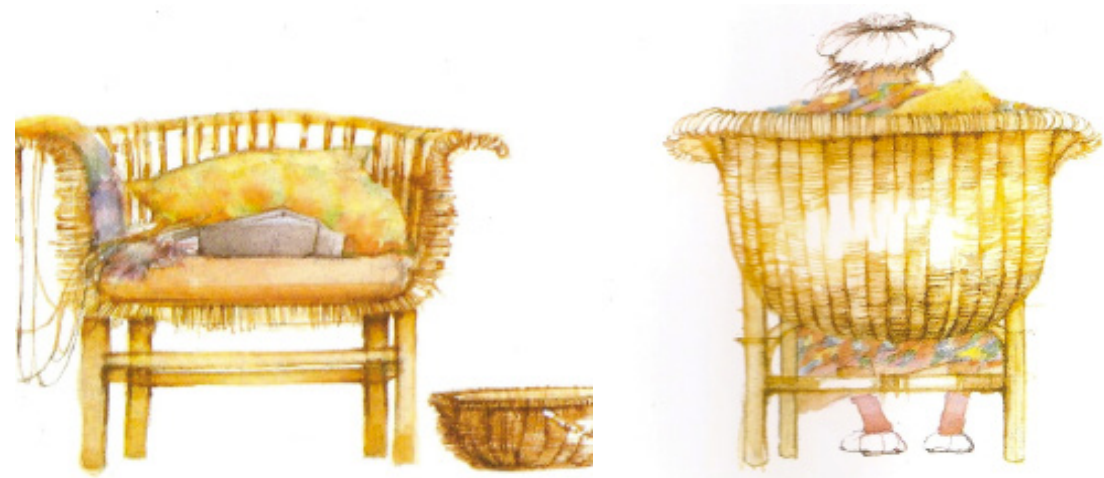

Fonte: Fox (2005)

Por outro lado, o idoso também é retratado, no decorrer da história, como alguém dependente. A criança teve que agir para poder ajudar a idosa vulnerável, e só a partir dessa ajuda é que ela foi capaz de recuperar sua memória. A história não tem a intenção de menosprezar

\footnotetext{
${ }^{3} \mathrm{~A}$ folha de guarda é a primeira página antes do início da narrativa. Para Nikolajeva e Scott (2011), os criadores de livros ilustrados têm descoberto possibilidades de uso das guardas como pretextos adicionais que contribuem para a história. Na maioria dos livros ilustrados, as guardas são brancas ou neutras, porém muitos autores veem nesse espaço possibilidades de uso como paratextos adicionais que contribuem de várias maneiras para a história.
} 
A FIGURA DO IDOSO NA LITERATURA INFANTIL: UM COMPARATIVO ENTRE AS OBRAS GUILHERME AUGUSTO ARAÚJO FERNANDES E VÓ, PARA DE FOTOGRAFAR!

o idoso, porém, baseia-se na representação social da velhice como um período de maior fragilidade, associando o velho a doenças e comportamentos menos autônomos.

Também é possível analisar a memória como fator chave de ligação intergeracional. Nesse sentido, a obra inverte os papéis do idoso e do jovem, fazendo este último ser o portador das memórias. O olhar sensível do livro está justamente nessa troca entre criança e idoso e na busca pelas memórias perdidas: "a experiência dos mais velhos precisa ser valorizada pelo resgate de suas lembranças e histórias que falam da vida, recuperando uma memória pessoal que é também coletiva" (FERNANDES, 2013, p. 1110).

Além disso, é possível afirmar que as gerações se conectam pela memória. Mesmo que partes de diferentes grupos familiares, o menino e a idosa possuem uma ligação de afeto. Ao ajudar a idosa a recuperar sua memória, Augusto rememora objetos importantes de sua família, promovendo uma troca mútua. Assim, infância e velhice são retratadas de modos completamente diferentes, tendo no tempo e nas vivências o elo entre os personagens.

Ainda em relação a Guilherme Augusto Araújo Fernandes, é interessante notar o diálogo entre texto e ilustração, conforme a imagem 4.

Figura 4: Dona Antônia Maria Diniz Cordeiro e Guilherme Augusto Araújo Fernandes

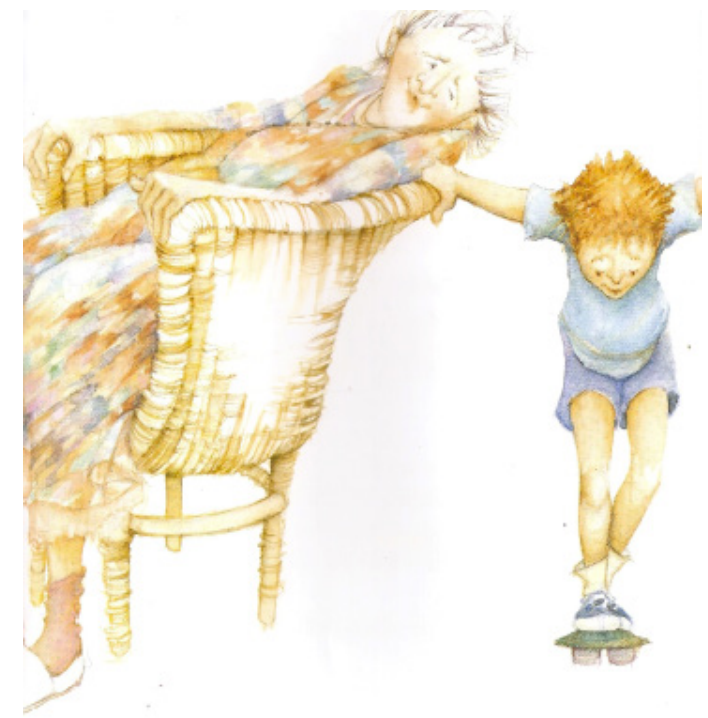

Fonte: Fox (2005)

As imagens são ricas em detalhes e também reforçam a ideia da dualidade entre infância e velhice, representando os idosos majoritariamente sentados e conferindo movimento ao protagonista. Porém, pensando além dessas características, de forma geral, texto verbal e imagem, mesmo não subvertendo totalmente o estereótipo da velhice, conseguem transmitir ao leitor a ligação e o afeto sentidos entre os personagens de diferentes épocas. 


\section{Vó, PARA DE FOTOGRAFAR!}

A segunda obra a ser analisada é intitulada Vó, para de fotografar!, da editora Melhoramentos. O livro faz parte do catálogo do Programa Nacional do Livro Didático (PNLD) do ano de 2018, recomendado para a Educação Infantil. A história é narrada em primeira pessoa, através da voz da neta, que sempre pedia para sua avó parar de fotografar. Ao contrário da obra anterior, nesta, os personagens são reconhecidos pelos seus papéis familiares, ou seja, não possuem nome próprio.

Figura 5: Vó, para de fotografar!

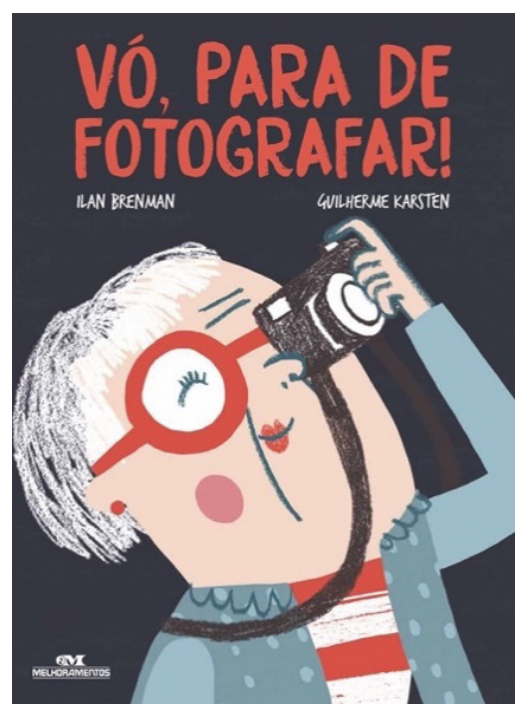

Fonte: Karsten (2017)

Durante a leitura, fica claro que a avó da história adora registrar momentos importantes: a festa à fantasia, o aniversário da prima, os animais do zoológico, o jogo de handebol, o parque de diversões, o banho de espuma da neta, as refeições com a família e a praia. A neta, por outro lado, está sempre pedindo para a avó parar de fotografar e não entende o porquê de a senhora estar sempre com a câmera ligada. Assim, a avó é representada como alegre e dinâmica, enquanto a menina parece estar sempre chateada e contrariada.

A apresentação visual da avó é significativa. Ela não apenas se move entre as cenas, como também muda de visual conforme a ocasião e, ainda, parece sempre disposta e ativa. A figura 6 é um compilado de três passagens do livro em que a avó, sorridente, registra diferentes momentos. A cena com o macaco, por exemplo, gera humor e mostra sua independência, reforçando a ideia de que a idade não se tornou um empecilho para a realização das atividades que deseja. Do mesmo modo, também há cenas engraçadas em que ela se fantasia de acordo com a ocasião, como no trecho do jogo de handebol. 
Figura 6: A representação da avó
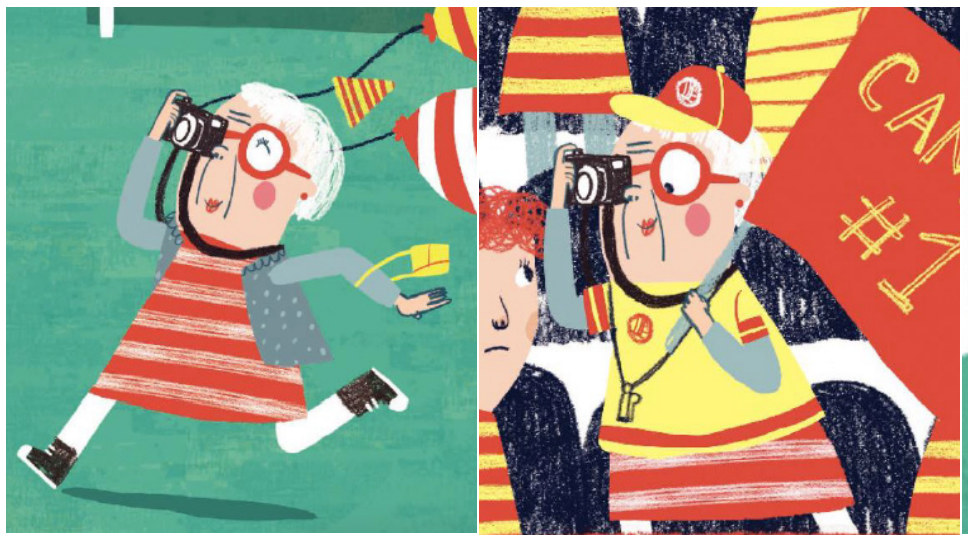

Fonte: Karsten (2017)

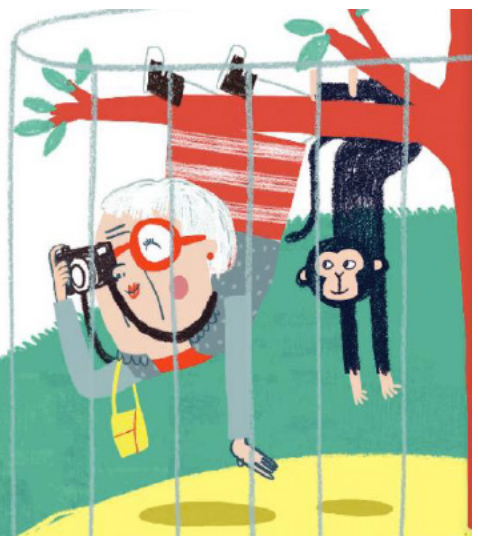

A avó também é retratada como uma pessoa participativa. Ela está sempre envolvida em passeios, eventos sociais e até mesmo vai ao parque de diversões fotografar o trem fantasma, destino costumeiramente associado às crianças. A idosa também não apresenta nenhum tipo de fragilidade ou submissão em relação à neta, visto que não atende a seus pedidos incansáveis sobre parar de fotografar. A neta, enquanto narradora e personagem participante da história, sempre diz: "Vó, para de fotografar!" (KARSTEN, 2017), mas a senhora nunca responde nem interrompe sua tarefa constante. Além disso, apesar dos óculos e dos cabelos brancos, ela se veste de forma despojada.

Figura 7: ilustração da avó fotografando a apresentação da neta

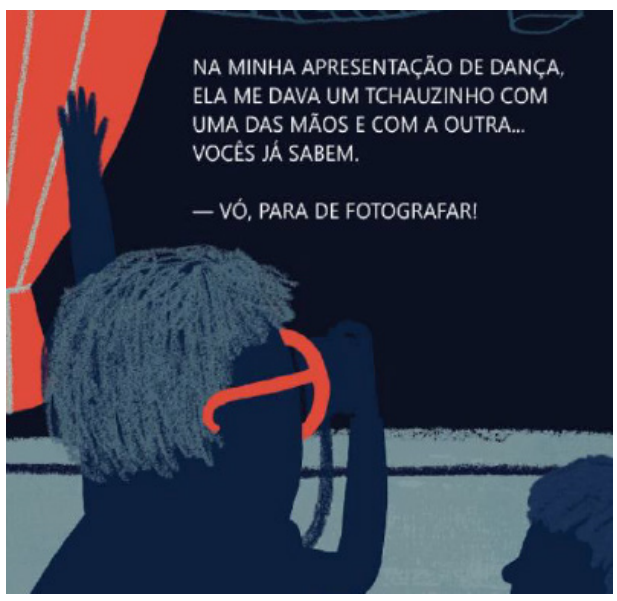

Fonte: Karsten (2017)

Na maior parte da história, a graça da narrativa se deve justamente ao modo como a avó é representada sem reforçar estereótipos e, ao mesmo tempo, como figura oposta à neta. Enquanto a avó está sempre sorridente, a menina é desenhada como se estivesse aborrecida. 
Mais do que isso: a avó é quem é ilustrada e descrita com movimento, de modo oposto à neta, quase sempre estática: "no zoológico, ela quase deu uma cambalhota macacal" (KARSTEN, 2017, p. 16) e "na praia eu imaginava que não haveria fotos, a minha vó não gosta de entrar na água. Assim que mergulhei, adivinhem quem estava lá?” (KARSTEN, 2017, p. 24).

Figura 8: oposições entre avó e neta em Vó, para de fotografar!
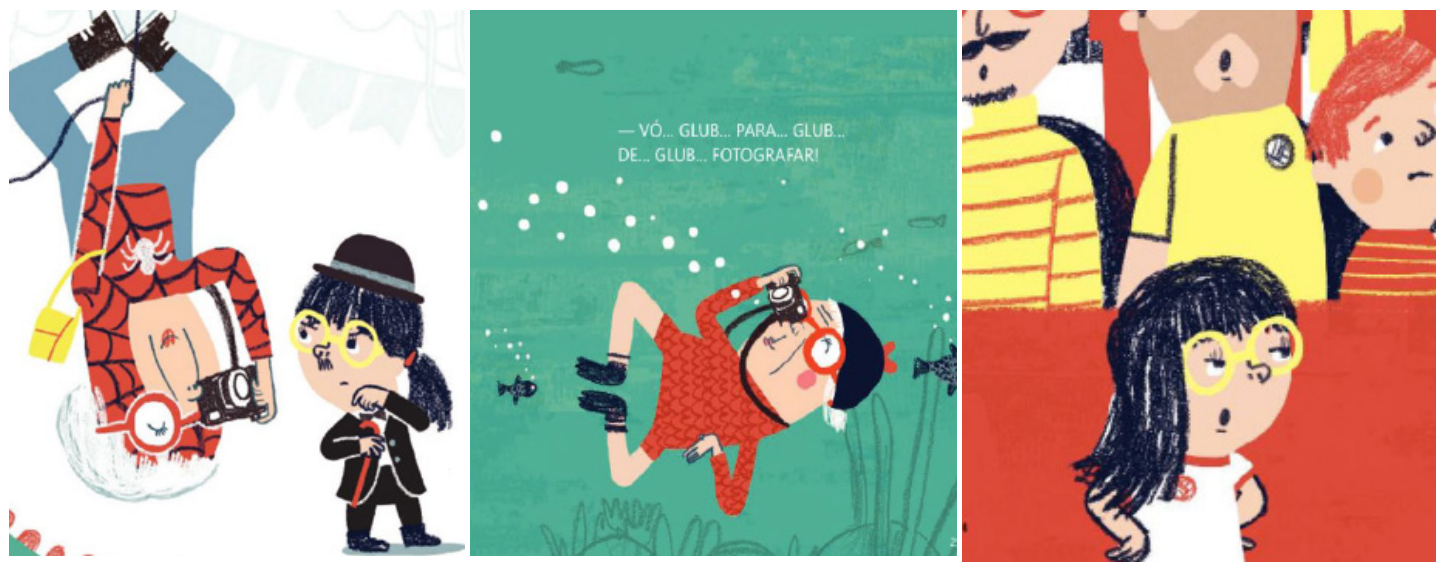

Fonte: Karsten (2017)

As diferenças entre a avó e a neta vão além da visualidade, mas podem ser percebidas principalmente por causa da ilustração. Nos elementos paratextuais, como na folha de guarda, o ilustrador brinca com um objeto em comum dessas duas personagens: os óculos. Assim, na abertura do livro e no final, o leitor atento aos detalhes irá perceber que os óculos vermelho da idosa possui um olho que remete a um sorriso porque está fechado e foi desenhado com uma linha côncava, enquanto os óculos amarelos da menina possuem um olho aberto e voltado para cima, como se estivesse revirando os olhos.

Figura 9: oposições entre os óculos da avó e os óculos da neta

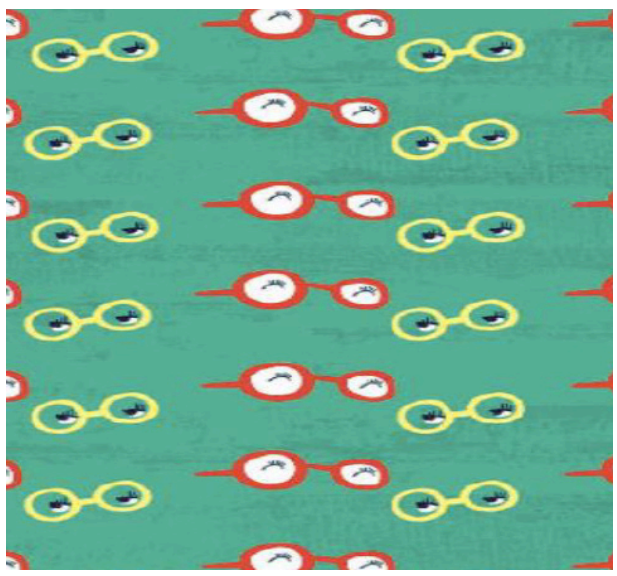

Fonte: Karsten (2017) 
A FIGURA DO IDOSO NA LITERATURA INFANTIL: UM COMPARATIVO ENTRE AS OBRAS GUILHERME AUGUSTO ARAÚJO FERNANDES E VÓ, PARA DE FOTOGRAFAR!

Toda a obra é permeada por detalhes que permitem que o leitor atento preencha as lacunas da história através de seus conhecimentos de mundo e daquilo que enxerga na obra. O livro ilustrado, portanto, torna-se não apenas um objeto cujas mensagens contribuem na produção de sentidos, mas um conjunto em que texto verbal, imagens e o próprio projeto gráfico dialogam (NIKOLAJEVA; SCOTT, 2011).

Ao final da narrativa, as intenções da avó com sua câmera fotográfica são descobertas. A idosa havia revelado todas as fotos tiradas ao longo de vários dias para montar um álbum de fotografias. A obra encerra com a ilustração da menina surpresa e avó abraçada nela mostrando o álbum que havia construído. Nessa parte, a menina, que também é narradora, permanece calada diante da surpresa da avó. Assim, o leitor precisa interpretar a cena unicamente por meio da narrativa visual. A última frase que encerra a obra apresenta a menina diferente sem a seriedade e aborrecimento das cenas anteriores - e reforça os laços intergeracionais da família: “Vó, não para nunca de fotografar! Eu te amo muito!" (KARSTEN, 2017, p. 29).

É importante destacar na narrativa que a avó, de forma não convencional, também é uma portadora de histórias e memórias. A narrativa atualiza o papel do idoso enquanto contador de histórias e cria uma personagem idosa que, para contar sobre o passado e eternizar acontecimentos, faz uso da tecnologia. A oralidade - como a ideia que temos do velho contador de histórias - é substituída pela visualidade, em um diálogo com a pós-modernidade. Por isso, o papel da avó como guardiã das memórias não se perde, apenas é renovado e atualizado. A idosa não é retratada como um ser passivo, mas como alguém dinâmica, que não apenas registra lembranças, mas também constrói sua própria história autêntica e inovadora, deixando seu legado e seus registros para as próximas gerações.

Nessa atualização da avosidade, é importante lembrar que o idoso une o início e o fim por meio da memória (FERNANDES, 2013). A coexistência de diferentes gerações e os novos papéis assumidos pelos personagens nas histórias da atualidade ajudam o leitor - criança e adulto - a refletir sobre a velhice e enxergar o idoso de uma forma menos padronizada. A conexão entre avó e neta, ao final da história, também remete à importância dos laços familiares entre idoso e criança que devem acontecer ainda na infância e são essenciais para a manutenção de conhecimentos, memórias e culturas.

\section{As VELHICES NA LITERATURA INFANTIL}

Em relação às duas obras analisadas, é possível fazer aproximações e apontar diferenças. Em ambas, há a presença do idoso, da criança e de um envolvimento afetivo entre diferentes gerações. Existe também uma temática voltada à memória que perpetua as duas histórias, pois ambas tratam do recordar ou do eternizar lembranças: "e os dois sorriram e sorriram, pois toda memória perdida de Dona Antônia tinha sido encontrada" (FOX, 2005, p. 29). 
No entanto, a memória é retratada diferentemente em cada uma das obras. Em Guilherme Augusto Araújo Fernandes, a criança é responsável por ajudar a idosa a lembrar de momentos passados, já em Vó, para de fotografar!, a personagem mais velha é quem, de forma independente e autônoma, tira fotos e monta um álbum de lembranças. Por diferentes caminhos, a interação que se dá entre as distintas idades acontece nas duas narrativas e promove uma conexão entre infância e velhice.

Para Izquierdo (2002), a memória significa aquisição, formação e conservação de informações. $O$ passado e aquilo de que nos lembramos e esquecemos também apontam para quem somos e permitem projetar o futuro. A memória, ao mesmo tempo que é coletiva, individualiza cada sujeito e é a partir dela que as tradições são mantidas e, ao mesmo tempo, transformadas.

Todos recordamos nossa rua, mas a rua de cada um foi diferente. Eu sou quem sou, cada um é quem é, porque todos lembramos de coisas que nos são próprias e exclusivas e não pertencem a mais ninguém. Nossas memórias fazem cada ser humano ou animal ser um ser único, um indivíduo. O acervo das memórias de cada um nos converte em indivíduos (IZQUIERDO, 2002, p. 15).

Nas duas histórias, as dualidades entre esquecimento e a lembrança, o registro e a posteridade interligam a velhice e a infância e conectam personagens distintos por meio do afeto. Essa representação da criança e do idoso é outro elemento que diferencia as duas obras. Enquanto, no primeiro livro, o idoso é representado geralmente estático, passivo, dependente e até mesmo doente, na segunda história, a velha é retratada como ativa, divertida e aventureira. Há uma larga diferença em relação a como o idoso é abordado nas duas narrativas, sendo a segunda a que mais ultrapassa ideias pré-concebidas.

Ainda na capa, a representação visual das idosas é marcante. Na obra Guilherme Augusto Araújo Fernandes, a idosa está sentada e olha para baixo, com uma atitude mais passiva e oposta à da criança. Já na capa de Vó, para de fotografar!, a avó possui uma ação mais dinâmica, além de estar sozinha, ela sorri e tem seu rosto direcionado para cima, transmitindo mais otimismo e vivacidade.

Outro aspecto importante: o menino da primeira obra não tem laços familiares com a idosa, enquanto na segunda história há personagens da mesma família. Há também diferença entre a maneira como as duas crianças tratam as idosas. Na obra de 1984, o menino, mesmo sem ser neto dos idosos da história, é atencioso e prestativo, dialoga com eles e ainda ajuda a Dona Antônia. Já na obra de 2017, a neta está sempre contrariada e ordena que a avó pare de fotografar, só modificando sua postura em relação a ela no final da história.

Além disso, as ilustrações têm um papel chave nas diferenciações entre as histórias. No desenho de Julie Vivas, há uso de cores mais claras, contrastes leves e traços delicados. Dona Antônia usa pantufa, camisolas e tem os cabelos brancos e despenteados. As imagens 
A FIGURA DO IDOSO NA LITERATURA INFANTIL: UM COMPARATIVO ENTRE AS OBRAS GUILHERME AUGUSTO ARAÚJO FERNANDES E VÓ, PARA DE FOTOGRAFAR!

são mais amenas e menos contrastantes, com predomínio de tons amarelados e pastéis. Já nas ilustrações de Ilan Brenman, há um nítido contraste com uso de cores opostas - vermelho e verde - que dão mais vivacidade à obra. A idosa de Vó, para de forografar! veste-se com tênis, vestido e casaco, usa uma bolsa amarela, domina equipamentos tecnológicos e tem um ar descontraído. Assim, imagem e texto verbal colaboram na geração de sentidos:

Tanto as palavras como as imagens deixam espaços para os leitores/ expectadores preencherem com seu conhecimento, experiência e expectativa anteriores, e assim podemos descobrir infinitas possibilidades de interação palavra-imagem (NIKOLAJEVA; SCOTT, 2011, p. 15).

$\mathrm{Na}$ figura 10, foram selecionadas as cores predominantes nas cenas de cada uma das obras. Com base na imagem, torna-se mais nítido o fato de que a primeira obra analisada conta com tons claros e mais sóbrios, enquanto a segunda utiliza cores opostas, deixando a obra mais descontraída e jovial.

Figura 10: paleta de cores predominantes em cada obra analisada

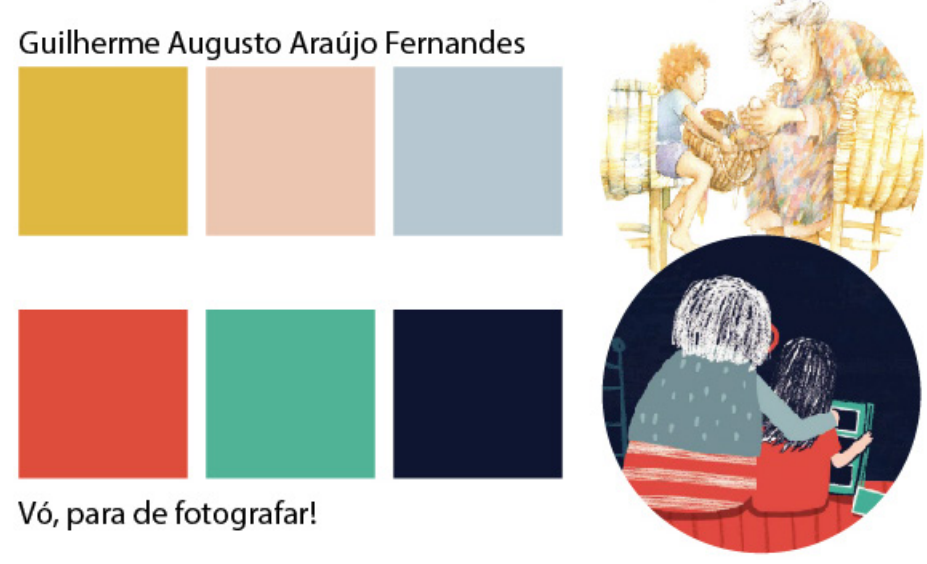

Fonte: elaboração própria (2021)

Independente das escolhas visuais de cada ilustrador, é importante salientar que as imagens dialogam e ampliam os sentidos do texto verbal. As cores, o tipo de traçado e a técnica de pintura são formas de reforçar o idoso representado em cada livro ilustrado. Cabe salientar ainda que o ponto de vista empregado em cada narrativa visual permite a cada leitor interpretar as histórias de uma forma única.

\section{CoNSIDERAÇõES FINAIS}

Ambas as histórias promovem uma reflexão sobre as interações, a sociedade, a velhice, a família. Constituídas por personagens velhos e jovens, as narrativas remetem à importância 
da memória na construção dos sujeitos e na manutenção da coletividade. Além disso, o que a comparação entre as histórias mostra é que a literatura, enquanto reflexo da sociedade, também se modifica. Por isso, a representação do idoso atual, mais ampla, não anula a obra de mais de trinta anos atrás, mas mostra que as mudanças, independentemente da velocidade em que acontecem, existem continuamente.

Ainda que com traços e narrativas diferentes, as duas obras se complementam. Assim como todos os idosos não são iguais à Dona Antônia, nem todos se parecem com a avó que fotografa. As concepções da construção de cada personagem com idade avançada também dialogam com a época em que cada obra foi escrita, visto que a velhice não se relaciona somente com a parte física do sujeito. De acordo com Beauvoir (2018 p. 18), "a velhice não poderia ser compreendida senão em sua totalidade; ela não é somente um fato biológico, mas também um fato cultural".

Além disso, nas duas narrativas, os ilustradores conferem às histórias pontos de vistas específicos, que vão além dos significados do texto, mas a segunda obra ganha destaque quando se trata de representar a idosa com mais dinamismo e independência. Também é interessante destacar que, apesar de a obra de Karsten se distanciar de estereótipos, a narrativa de Mem, escrita décadas atrás, não está equivocada, afinal, a velhice é heterogênea porque cada sujeito se constitui como um ser único.

Dar maior visibilidade ao idoso nas obras infantis ilustradas é uma forma de promover uma reflexão sobre a velhice. $O$ modo como essas figuras são retratadas influencia na visão que o leitor constrói sobre essa fase da vida, que pode ser estagnada ou ampliada. Também permite que o idoso, tantas vezes marginalizado, assuma um novo lugar, reforçando a ideia da necessidade de criação de uma sociedade mais inclusiva, com espaços acessíveis, humanizados e acolhedores a cada um deles (WORLD HEALTH ORGANIZATION, 2005). Por fim, o resultado dessa análise aponta para um caminho importante de leitura: mais do que definir quem é a pessoa idosa de cada época, é preciso reconhecer que a velhice é composta por pessoas plurais, e tal singularidade deve ser respeitada e valorizada, não circunscrevendo as pessoas que estão na velhice a rótulos engessados que tendem a limitar as possibilidades de viver essa fase da vida de maneira mais autônoma efetivamente.

\section{REFERÊNCIAS}

ALVES, R. As cores do crepúsculo: a estética do envelhecer. 8. ed. Campinas: Papirus, 2008.

BALTES, P. Theoretical propositions of the lifespan developmental psychology: on the dynamics between growth and decline. Developmental Psychology, v. 23 n. 5, p. 611-696, 1987.

BAUMAN, Z. Modernidade líquida. São Paulo: Zahar, 2001. 
A FIGURA DO IDOSO NA LITERATURA INFANTIL: UM COMPARATIVO ENTRE AS OBRAS GUILHERME AUGUSTO ARAÚJO FERNANDES E VÓ, PARA DE FOTOGRAFAR!

BEAUVOIR, S. A velhice. Tradução Maria Helena Franco Martins. 3. ed. Rio de Janeiro: Nova Fronteira, 2018.

FEIXA, C. F.; LECCARDI, C. O conceito de geração nas teorias sobre juventude. In: Revista Sociedade e Estado. v. 25, n. 2., ago. 2010.

FERNANDES, C. R. D. Avós e Netos na Literatura Infantil: vidas compartilhadas. Educação \& Realidade, Porto Alegre, v. 38, n. 4, p. 1089-1112, out./dez. 2013.

FERREIRA, C. P. S.; et al. A visão do envelhecimento, da velhice e do idoso veiculada por livros infanto-juvenis. Saúde e Sociedade (Online), v. 24, p. 1061-1075, 2015.

FOX, M. Guilherme Augusto Araújo Fernandes. São Paulo: Brinque-Book, 2005.

GUARESCHI, P. A. Representações sociais: avanços teóricos e epistemológicos. Social representations: theoretical and epistemological developments. Temas psicol., Ribeirão Preto, v.8, n. 3, p. 249-256, dez. 2000.

IZQUIERDO, I. Memória. Porto Alegre: Artmed, 2002.

KARSTEN, G. Vó para de fotografar!. São Paulo: Melhoramentos, 2017.

MÃE, V. H. A máquina de fazer espanhóis. São Paulo: Biblioteca Azul, 2016.

NIKOLAJEVA, M.; SCOTT, C. Livro ilustrado: palavras e imagens. São Paulo: Cosac Naify, 2011.

OLIVEIRA, R. Pelos jardins Boboli: reflexões sobre a arte de ilustrar livros para crianças e jovens. Rio de Janeiro: Nova Fronteira, 2008.

RAMOS, A. C. Os Avós na Literatura Infantil: perspectivas gerontológicas e educacionais. Educação \& Realidade, Porto Alegre, v. 40, n. 1, p. 191-225, jan./mar. 2015.

REIS, P. O; CEOLIM, M.F. O significado atribuído a 'ser idoso' por trabalhadores de instituições de longa permanência. Revista da Escola de Enfermagem da USP, São Paulo, v. 41, n. 1, p. 57-64, 2007.

WORLD HEALTH ORGANIZATION. Envelhecimento ativo: uma política de saúde. tradução Suzana Gontijo. Brasília: Organização Pan-Americana da Saúde, 2005.

Recebido para publicação em: 18 abr. 2021.

Aceito para publicação em: 8 nov. 2021. 